Short communication

\title{
Exposure of bremsstrahlung from beta-emitting therapeutic radionuclides
}

\author{
H.C. Manjunatha*, B. Rudraswamy \\ Department of Physics, Bangalore University, Bangalore-560056, Karnataka, India
}

\section{A R T I C L E I N F O}

\section{Article history:}

Received 26 September 2007

Received in revised form

15 May 2008

Accepted 19 January 2009

\section{Keywords:}

Bremsstrahlung

Beta

Radionuclide

\begin{abstract}
A B S T R A C T
There has been an increased interest in beta therapeutic nuclear medicine, which emits relatively highenergy ( $>1 \mathrm{MeV}$ ) $\beta$-rays and the production in vivo of Bremsstrahlung sufficient for external imaging, the produced Bremsstrahlung radiation hazard warrants evaluation. The Bremsstrahlung dose from patient administered $\beta$-ray emitted radionuclide has been calculated by extending the national council on Radiation Protection and measurement model of a point source in air to account for biologic elimination of activity. We have estimated the probability of bremsstrahlung production, specific Bremsstrahlung constant (defined by Zanzonico et al.) and activity $\left(A_{\text {release }}\right)$ in bone cortical, bone compact, different regions of tooth enamel (enamel dentin junction (EDJ), enamel middle surface, enamel inner surface), different regions of dentin (outer surface, middle surface, enamel dentin junction (EDJ)), soft tissue, lungs and skeleton for different therapeutic beta-emitting radionuclide. In the present calculations we have used modified atomic number $\left(Z_{\mathrm{mod}}\right)$ defined for bremsstrahlung process.

Proper localization and quantification of incorporated beta emitters in bone and tooth are possible, because Bremsstrahlung production is greater in bone and tooth than soft tissue due to their high modified atomic number $\left(Z_{\text {mod }}\right)$. Radionuclide therapy with pure $\beta$-ray emitters emitted in bone, tooth, soft tissue, lungs and skeleton does not require medical confinement of patients for radiation protection. (C) 2009 Elsevier Ltd. All rights reserved.
\end{abstract}

\section{Introduction}

With an increasing interest in therapeutic nuclear medicine, application of incorporated beta-emitting nuclides has been observed to have extremely high potential in treatment of both malignant and non-malignant conditions. In malignant conditions tumour specific metabolic and biological characteristics are effectively deployed to optimize the targeting of radionuclides and hence permit the successful therapy. A therapeutic radionuclide should emit principally non-penetrating radiations (i.e., particles such as $\beta$-rays) to maximize self-irradiation of the target region and minimize irradiation of non-target regions. Increasingly, pure $\beta$-ray emitters (Table 1) are being considered and used as therapeutic radionuclides (Webber et al., 1989; Fritzberg and Wessels, 1995).

In the instances where beta-emitting radionuclides are used for therapy of non-malignant conditions, the specific area of current interest relates to application of radionuclides in radiosynovictomy. This includes the treatment of subtle painful conditions associated with disease of joints such as rheumatoid arthritis or villonodular synovitis (Franssen et al., 1989; Vont Pad Bosch et al., 1981). Betaemitting nuclides such as ${ }^{90} \mathrm{Y},{ }^{32} \mathrm{P},{ }^{165} \mathrm{D}$ etc. offer clinically proven

\footnotetext{
* Corresponding author.

E-mail address: manjunathhc@rediffmail.com (H.C. Manjunatha).
}

and cost effective alternative to surgical synovictomy (RodriguesMerchan et al., 1997; Lofquist et al., 1997).

Uchiyama et al. (1997) reported that Strontium-89 chloride is being widely used as a palliative treatment for patients with bone pain caused by bone metastases. A Zeeman atomic absorption spectrometry study shows that some extent of strontium also presents in the human body (Patrick et al., 1996). The radionuclides such as ${ }^{89} \mathrm{Sr}$ and ${ }^{32} \mathrm{P}$ have also been successfully and effectively utilized to provide palliative therapy to patients with multifocal skeletal metastatic lesions in cases of breast and prostatic cancers. Furthermore ${ }^{90} \mathrm{Y}$ appears to be a potential beta-emitting radionuclide, which has been shown to offer attractive considerations for being used in radioimmunotherapy (Stewart et al., 1988). Betaemitting radionuclide like ${ }^{32} \mathrm{P}$ also finds application in infusional brachytherapy (Hien Nguyen et al., 1997).

Markowicz and VanGriken (1984) proposed a new expression for external Bremsstrahlung (EB) intensity (I) and modified atomic number $\left(Z_{\mathrm{mod}}\right)$ for a compound to taking into account the self absorption of Bremsstrahlung and electron back scattering

$I=\operatorname{Con} \frac{\Delta E}{E_{\gamma}} Z_{\bmod }\left(E_{0}-E_{\gamma}\right)[1-f]$

where $E_{\nu}$ and $E_{0}$ are emitted photon energy and incident electron energy respectively and $f$ is a function of $E_{0}, E_{\nu}$ and composition. In above equation (1), $Z_{\text {mod }}$ is 
Table 1

Physical properties of $\beta$-ray emitters for radionuclide therapy.

\begin{tabular}{|c|c|c|c|c|}
\hline Source & Half-life (in days) & $E_{\max }(\mathrm{MeV})$ & $E_{\mathrm{Br}}(\mathrm{MeV})$ & Frequency of emission $\left(f_{\beta}\right)_{i} /$ transformation \\
\hline$\overline{Y^{90}}$ & 2.67 & 2.28 & 0.258 & 1 \\
\hline $\mathrm{Pm}^{143}$ & 13.60 & 0.93 & 0.102 & 1 \\
\hline $\mathrm{Er}^{169}$ & 9.40 & 0.35 & 0.038 & 1 \\
\hline $\mathrm{Ti}^{204}$ & 1387 & 0.77 & 0.084 & 1 \\
\hline $\mathrm{Bi}^{210}$ & 5.01 & 1.16 & 0.127 & 1 \\
\hline $\mathrm{Sr}^{89}$ & 50.5 & 1.49 & 0.163 & 1 \\
\hline $\mathrm{Ca}^{45}$ & 163 & 0.25 & 0.028 & 1 \\
\hline
\end{tabular}

Table 2

Composition of bone (in percentage).

\begin{tabular}{llc}
\hline Element & Bone compact & Bone cortical \\
\hline $\mathrm{H}$ & 6.398 & 4.723 \\
$\mathrm{C}$ & 27.800 & 14.43 \\
$\mathrm{~N}$ & 2.700 & 4.199 \\
$\mathrm{O}$ & 41.001 & 44.609 \\
$\mathrm{Mg}$ & 0.200 & 0.270 \\
$\mathrm{P}$ & 0.700 & 10.497 \\
$\mathrm{~S}$ & 0.200 & 0.315 \\
$\mathrm{Ca}$ & 14.700 & 20.993 \\
$\mathrm{Zn}$ & - & 0.011 \\
\hline
\end{tabular}

Table 3

Composition of dentin (in percentage).

\begin{tabular}{llll}
\hline Element & Outer surface & Middle surface & Enamel dentin junction (EDJ) \\
\hline $\mathrm{C}$ & 38.590 & 36.280 & 37.050 \\
$\mathrm{O}$ & 32.590 & 34.210 & 34.510 \\
$\mathrm{Na}$ & 0.240 & 0.440 & 0.660 \\
$\mathrm{Mg}$ & 0.160 & 0.230 & 0.220 \\
$\mathrm{P}$ & 10.670 & 10.860 & 10.460 \\
$\mathrm{Cl}$ & 0.390 & 0.250 & 0.090 \\
$\mathrm{Ca}$ & 17.360 & 17.740 & 16.990 \\
\hline
\end{tabular}

$Z_{\text {mod }}=\frac{\sum_{i}^{l} \frac{W_{i} Z_{i}^{2}}{A_{i}}}{\sum_{i}^{l} \frac{W_{i} Z_{i}}{A_{i}}}$

where $W_{i}, Z_{i}$ and $A_{i}$ are weight fraction, atomic number and mass number of $i$ th element respectively. Shivaramu (1990) experimentally measured the effective atomic number $\left(Z_{\text {eff }}\right)$ for compounds from the measured EB yields and found that it agrees with $Z_{\text {mod. }}$.

The incorporated radio therapeutic beta-emitting nuclides produces Bremsstrahlung radiation and could have different energies and intensities. Bremsstrahlung yield is a function of two components namely Internal Bremsstrahlung and external Bremsstrahlung. The intensity of external Bremsstrahlung largely depends on the energy of the emitted beta particles and atomic number of the surrounding matrix material. On the other hand
Table 5

Composition of soft tissue, lungs and skeleton (in percentage).

\begin{tabular}{lccr}
\hline Element & Skeleton & Soft tissue & Lungs \\
\hline $\mathrm{H}$ & 7.337 & 10.454 & 10.134 \\
$\mathrm{C}$ & 24.475 & 22.663 & 10.238 \\
$\mathrm{~N}$ & 3.057 & 2.490 & 2.866 \\
$\mathrm{O}$ & 47.893 & 63.527 & 75.752 \\
$\mathrm{~F}$ & 0.025 & 0.000 & 0.000 \\
$\mathrm{Na}$ & 0.326 & 0.112 & 0.184 \\
$\mathrm{Mg}$ & 0.112 & 0.013 & 0.007 \\
$\mathrm{Si}$ & 0.002 & 0.030 & 0.006 \\
$\mathrm{P}$ & 5.095 & 0.134 & 0.080 \\
$\mathrm{~S}$ & 0.173 & 0.204 & 0.225 \\
$\mathrm{Cl}$ & 0.143 & 0.133 & 0.266 \\
$\mathrm{~K}$ & 0.153 & 0.208 & 0.194 \\
$\mathrm{Ca}$ & 10.190 & 0.024 & 0.009 \\
\hline
\end{tabular}

\section{Table 6}

Evaluated modified atomic number $\left(Z_{\text {mod }}\right)$ different portions of teeth.

\begin{tabular}{lr}
\hline Region & $Z_{\text {mod }}$ \\
\hline Enamel Outer surface & 10.091 \\
Enamel Middle & 10.197 \\
(EDJ) Enamel & 10.053 \\
(EDJ) Dentin & 7.768 \\
Dentin middle & 8.508 \\
Dentin inner surface & 8.603 \\
Bone cortical & 11.697 \\
Bone compact & 9.197 \\
Soft Tissue & 7.064 \\
Skeleton & 8.001 \\
Lung & 6.585 \\
\hline
\end{tabular}

internal Bremsstrahlung component inherently depends on the interaction of the emitted beta particle with the nucleus of the source radionuclide itself. It can therefore be stated that the photon characteristics of external Bremsstrahlung depend on the surrounding matrix material whereas those of internal Bremsstrahlung would depend on the emission characteristics of radionuclide. Bremsstrahlung produced in vivo is sufficient for external detection and imaging. The resulting external radiation hazard may therefore be some of concern, at least theoretically, and should be systematically evaluated.

Table 4

Composition of enamel (in percentage).

\begin{tabular}{|c|c|c|c|}
\hline Element & Enamel dentin junction (EDJ) & Enamel middle surface & Enamel inner surface \\
\hline $\bar{C}$ & 59.000 & 52.270 & 49.840 \\
\hline $\mathrm{O}$ & 30.670 & 30.570 & 33.540 \\
\hline $\mathrm{Na}$ & 0.470 & 0.420 & 0.360 \\
\hline $\mathrm{Mg}$ & 0.250 & 0.340 & 0.450 \\
\hline $\mathrm{P}$ & 4.410 & 6.230 & 6.320 \\
\hline $\mathrm{Cl}$ & - & - & - \\
\hline $\mathrm{Ca}$ & 5.190 & 9.150 & 9.500 \\
\hline
\end{tabular}


Table 7

Specific bremsstrahlung constant for tooth \& bone, $\Gamma_{\mathrm{Br}}$ (in $\mathrm{C} / \mathrm{kg}-\mathrm{cm}^{2} / \mathrm{MBq}-\mathrm{h}$ ).

\begin{tabular}{|c|c|c|c|c|c|c|c|c|}
\hline Radio nuclide & Bone cortical & Bone compact & Enamel outer surface & Enamel middle & (EDJ) Enamel & (EDJ) Dentin & Dentin middle & Dentin inner surface \\
\hline$\overline{Y^{90}}$ & $2.93 \times 10^{-3}$ & $2.3 \times 10^{-3}$ & $2.53 \times 10^{-3}$ & $2.55 \times 10^{-3}$ & $2.46 \times 10^{-4}$ & $1.94 \times 10^{-4}$ & $2.13 \times 10^{-3}$ & $2.15 \times 10^{-3}$ \\
\hline $\mathrm{Pm}^{143}$ & $2.67 \times 10^{-4}$ & $2.09 \times 10^{-4}$ & $2.30 \times 10^{-4}$ & $2.32 \times 10^{-4}$ & $2.29 \times 10^{-4}$ & $1.77 \times 10^{-4}$ & $1.94 \times 10^{-4}$ & $1.96 \times 10^{-4}$ \\
\hline $\mathrm{Er}^{169}$ & $4.20 \times 10^{-5}$ & $3.30 \times 10^{-5}$ & $3.62 \times 10^{-5}$ & $3.66 \times 10^{-5}$ & $3.61 \times 10^{-5}$ & $2.78 \times 10^{-5}$ & $3.06 \times 10^{-5}$ & $3.09 \times 10^{-5}$ \\
\hline $\mathrm{Ti}^{204}$ & $7.66 \times 10^{-7}$ & $6.02 \times 10^{-7}$ & $6.61 \times 10^{-7}$ & $6.68 \times 10^{-6}$ & $6.58 \times 10^{-6}$ & $5.08 \times 10^{-6}$ & $5.57 \times 10^{-7}$ & $5.64 \times 10^{-7}$ \\
\hline $\mathrm{Bi}^{210}$ & $7.35 \times 10^{-5}$ & $5.78 \times 10^{-5}$ & $8.14 \times 10^{-5}$ & $6.40 \times 10^{-5}$ & $6.31 \times 10^{-5}$ & $4.88 \times 10^{-5}$ & $5.34 \times 10^{-4}$ & $5.41 \times 10^{-5}$ \\
\hline $\mathrm{Sr}^{89}$ & $2.09 \times 10^{-7}$ & $1.65 \times 10^{-7}$ & $1.81 \times 10^{-7}$ & $1.83 \times 10^{-7}$ & $1.80 \times 10^{-7}$ & $1.39 \times 10^{-7}$ & $1.52 \times 10^{-7}$ & $1.54 \times 10^{-7}$ \\
\hline $\mathrm{Ca}^{45}$ & $2.2 \times 10^{-12}$ & $1.7 \times 10^{-12}$ & $6.18 \times 10^{-12}$ & $1.97 \times 10^{-12}$ & $1.9 \times 10^{-12}$ & $1.4 \times 10^{-12}$ & $1.6 \times 10^{-12}$ & $1.6 \times 10^{-12}$ \\
\hline
\end{tabular}

Table 8

Specific bremsstrahlung constant for soft tissue, lungs and skeleton, $\Gamma_{\mathrm{Br}}$ (in $\left.\mathrm{C} / \mathrm{kg}-\mathrm{cm}^{2} / \mathrm{MBq}-\mathrm{h}\right)$.

\begin{tabular}{llll}
\hline Radio nuclide & Soft tissue & Lungs & Skeleton \\
\hline $\mathrm{Y}^{90}$ & $1.77 \times 10^{-3}$ & $1.65 \times 10^{-3}$ & $2.00 \times 10^{-3}$ \\
$\mathrm{Pm}^{143}$ & $1.61 \times 10^{-4}$ & $1.50 \times 10^{-4}$ & $1.82 \times 10^{-4}$ \\
$\mathrm{Er}^{169}$ & $2.54 \times 10^{-5}$ & $2.36 \times 10^{-5}$ & $2.87 \times 10^{-5}$ \\
$\mathrm{Ti}^{204}$ & $4.62 \times 10^{-7}$ & $4.31 \times 10^{-7}$ & $5.24 \times 10^{-7}$ \\
$\mathrm{Bi}^{210}$ & $4.43 \times 10^{-5}$ & $4.13 \times 10^{-5}$ & $5.02 \times 10^{-5}$ \\
$\mathrm{Sr}^{89}$ & $1.26 \times 10^{-7}$ & $1.18 \times 10^{-7}$ & $1.43 \times 10^{-7}$ \\
$\mathrm{Ca}^{45}$ & $1.34 \times 10^{-12}$ & $1.25 \times 10^{-12}$ & $1.52 \times 10^{-12}$ \\
\hline
\end{tabular}

\section{Materials and methods}

The Bremsstrahlung dose equivalent from a radio activity-containing patient in overall bone and tissue may be estimated using (Zanzonico et al., 1999) following equations

$D_{\mathrm{Br}}(1 \mathrm{~m}, \infty)=\frac{34.6 Q_{0} \Gamma_{\mathrm{Br}} T 0.25}{(100 \mathrm{~cm})^{2}}\left(1-\Phi_{\mathrm{Br}}\right)$

$\left(A_{\text {release }}\right)_{\mathrm{Br}}=\frac{580}{\Gamma_{\mathrm{Br}} T\left(1-\Phi_{\mathrm{Br}}\right)}$

where $D_{\mathrm{Br}}(1 \mathrm{~m}, \infty)$ is bremsstrahlung effective dose equivalent (in $\mathrm{cSv}$ ) at a distance of $1 \mathrm{~m}$ from the patient; $\left(A_{\text {release }}\right)_{\mathrm{Br}}$ is activity $(\mathrm{MBq})$ above which patient should remain hospitalized on the basis of the projected bremsstrahlung effective dose equivalent; $T$ is effective half-life of radionuclide; $Q_{0}$ is initial activity (in $\mathrm{MBq}$ ) in the point source; $\Phi_{\mathrm{Br}}$ is average total body (TB)-to-TB absorption fraction for bremsstrahlung of average energy $E_{\mathrm{Br}}$ and $\Gamma_{\mathrm{Br}}$ equals "specific bremsstrahlung constant"(in $\mathrm{C} / \mathrm{kg}-\mathrm{cm}^{2} / \mathrm{MBq}-\mathrm{h}$ ) of the radionuclide, that is the bremsstrahlung exposure rate (in $\mathrm{C} / \mathrm{Kg} / \mathrm{h}$ ) at a distance of $1 \mathrm{~cm}$ from a $1-\mathrm{MBq}$ beta ray point source and it is given by following equations

$\Gamma_{\mathrm{Br}}=\sum_{i=1}^{n}\left(f_{\beta}\right)_{i}\left[\left(P_{\mathrm{Br}}\right)_{\beta}\right]_{i} \Gamma_{\mathrm{Br}}\left[\left(E_{\mathrm{Br}}\right)_{\beta}\right]_{i}$

$\left[\left(P_{\mathrm{Br}}\right)_{\beta}\right]_{i}=\frac{Z_{\bmod }\left[\left(E_{\max }\right)_{\beta}\right]_{i}}{3000}$
Table 10

Probability of radiative energy loss of $\beta$-ray $\left[\left(P_{\mathrm{Br}}\right)_{\beta}\right]$ for soft tissue, lung and skeleton (in $\mathrm{keV}$ ).

\begin{tabular}{llll}
\hline Radio nuclide & Soft tissue & Lung & Skeleton \\
\hline $\mathrm{Y}^{90}$ & 5.36 & 5.00 & 6.08 \\
$\mathrm{Pm}^{143}$ & 2.18 & 2.04 & 2.48 \\
$\mathrm{Er}^{169}$ & 8.24 & 7.68 & 9.33 \\
$\mathrm{Ti}^{204}$ & 1.81 & 1.69 & 2.05 \\
$\mathrm{Bi}^{210}$ & 2.73 & 2.54 & 3.09 \\
$\mathrm{Sr}^{89}$ & 3.05 & 3.27 & 3.97 \\
$\mathrm{Ca}^{45}$ & 0.58 & 5.48 & 6.66 \\
\hline
\end{tabular}

$\left[\left(E_{\mathrm{Br}}\right)_{\beta}\right]_{i}=0.11\left[\left(E_{\max }\right)_{\beta}\right]_{i}$

where $\left[\left(P_{\mathrm{Br}}\right)_{\beta}\right]_{i}$ is probability of radiative loss by $\beta$-ray $i ; Z_{\text {mod }}$ is modified atomic number defined for bremsstrahlung process given by Markowicz et al. (1984). We have evaluated $Z_{\text {mod }}$ for bone cortical, bone compact, tooth enamel, dentin, soft tissue, lungs and skeleton using composition given in Tables 2-5 \& Markowicz formula (equation (2)). The evaluated values of $Z_{\bmod }$ are tabulated in Table 6. $\left(f_{\beta}\right)_{i}$ is frequency of emission(i.e., the number per nuclear transformation) of $\beta$-ray $i$. $\left[\left(E_{\mathrm{Br}}\right)_{\beta}\right]_{i}$ is mean energy (in $\mathrm{MeV}$ ) of bremsstrahlung for $\beta$-ray $i$ emitted by a radionuclide. The spectrum, which indicates the energy window equal to mean energy of bremsstrahlung $\pm 25 \%$ can be used for imaging without collimation. $\left[\left(E_{\max }\right)_{\beta}\right]_{I}$ is max initial kinetic energy of $\beta$-ray $i$.

$\Gamma_{\mathrm{Br}}\left[\left(E_{\mathrm{Br}}\right)_{\beta}\right]_{i}$ is specific Bremsstrahlung constant (in $\mathrm{C} / \mathrm{kg}-\mathrm{cm}^{2} /$ $\mathrm{MBq}-\mathrm{h})$ of $\beta$-ray yielding Bremsstrahlung of mean energy $\left[\left(E_{\mathrm{Br}}\right)_{\beta}\right]_{i}$. The estimation of the specific bremsstrahlung constant based on the bremsstrahlung mean energy rather than the actual bremsstrahlung spectrum, is a gross approximation. The energy dependent $\Gamma_{\mathrm{Br}}\left[\left(E_{\mathrm{Br}}\right)_{\beta}\right]_{i}$ corresponds to the conventional energy dependent specific ray constant (Johns and Cunningham, 1969). The term $\left(1-\Phi_{\mathrm{Br}}\right)$ is the fraction of photon energy of energy $E_{\gamma}$, which is not absorbed within the total body (TB), and is thus used to approximate the effect of shielding by the patient. A compilation of TB/TB absorbed fraction as a function of photon energy and TB mass is presented by Zanzonico et al. (1995) as adopted from Christy and Eckerman (1987); absorbed fractions for photon energies and TB

Table 9

Probability of radiative energy loss of $\beta$-ray $\left[\left(P_{\mathrm{Br}}\right)_{\beta}\right]$ for tooth \& bone (in keV).

\begin{tabular}{|c|c|c|c|c|c|c|c|c|}
\hline Radio nuclide & Bone cortical & Bone compact & Enamel outer surface & Enamel middle & (EDJ) Enamel & (EDJ) Dentin & Dentin middle & Dentin inner surface \\
\hline$\overline{Y^{90}}$ & 8.89 & 6.98 & 7.66 & 7.74 & 7.64 & 5.90 & 6.46 & 6.54 \\
\hline $\mathrm{Pm}^{143}$ & 3.62 & 2.85 & 3.12 & 3.16 & 3.11 & 2.40 & 2.63 & 2.66 \\
\hline $\mathrm{Er}^{169}$ & 1.36 & 1.07 & 1.17 & 1.18 & 1.17 & 9.06 & 9.92 & 1.00 \\
\hline $\mathrm{Ti}^{204}$ & 3.00 & 2.36 & 2.59 & 2.61 & 2.58 & 1.99 & 2.18 & 2.20 \\
\hline $\mathrm{Bi}^{210}$ & 4.52 & 3.55 & 3.90 & 3.94 & 3.88 & 3.00 & 3.28 & 3.32 \\
\hline $\mathrm{Sr}^{89}$ & 5.80 & 4.56 & 5.01 & 5.06 & 4.99 & 3.85 & 4.22 & 4.27 \\
\hline $\mathrm{Ca}^{45}$ & 0.97 & 0.76 & 0.84 & 0.87 & 8.61 & 6.47 & 7.09 & 7.17 \\
\hline
\end{tabular}


Table 11

$A_{\text {release }}$ in bone and tooth (in $\mathrm{MBq}$ ).

\begin{tabular}{|c|c|c|c|c|c|c|c|c|}
\hline Radio nuclide & Bone cortical & Bone compact & Enamel outer surface & Enamel middle & (EDJ) Enamel & (EDJ) Dentin & Dentin middle & Dentin inner surface \\
\hline$\overline{Y^{90}}$ & 75495 & 96352 & 87787 & 87133 & 90247 & 11406 & 104118 & 80532 \\
\hline $\mathrm{Pm}^{143}$ & 164530 & 209374 & 190704 & 188738 & 191498 & 247872 & 222858 & 223652 \\
\hline $\mathrm{Er}^{169}$ & 162251 & 2063257 & 1879822 & 1862224 & 1890080 & 2229801 & 2229801 & 2208152 \\
\hline $\mathrm{Ti}^{204}$ & 544377 & 743373 & 677368 & 670371 & 680559 & 881512 & 803964 & 793986 \\
\hline $\mathrm{Bi}^{210}$ & 1624851 & 2066766 & 1466295 & 1866548 & 1893170 & 2447932 & 2237061 & 2208116 \\
\hline $\mathrm{Sr}^{89}$ & 56412159 & 71739594 & 65386331 & 64714602 & 65647296 & 84955324 & 77606633 & 76701892 \\
\hline $\mathrm{Ca}^{45}$ & $1799 \times 10^{9}$ & $2289 \times 10^{9}$ & $6474 \times 10^{9}$ & $2304 \times 10^{9}$ & $2057 \times 10^{9}$ & $2711 \times 10^{9}$ & $2475 \times 10^{9}$ & $2452 \times 10^{9}$ \\
\hline
\end{tabular}

Table 12

$A_{\text {release }}$ in soft tissue, lungs and skeleton (in MBq).

\begin{tabular}{llll}
\hline Radio nuclide & Soft tissue & Lungs & Skeleton \\
\hline $\mathrm{Y}^{90}$ & 125459 & 110707 & 134578 \\
$\mathrm{Pm}^{143}$ & 272544 & 240550 & 292303 \\
$\mathrm{Er}^{169}$ & 2685555 & 2371634 & 2881415 \\
$\mathrm{Ti}^{204}$ & 969281 & 854269 & 1038034 \\
$\mathrm{Bi}^{210}$ & 2691125 & 2375404 & 2886321 \\
$\mathrm{Sr}^{89}$ & 93470972 & 82528029 & 100201136 \\
$\mathrm{Ca}^{45}$ & $2980 \times 10^{9}$ & $2631 \times 10^{9}$ & $3197 \times 10^{9}$ \\
\hline
\end{tabular}

masses not tabulated may be estimated by interpolation between the appropriate table entries.

The Specific bremsstrahlung constant (in $\mathrm{C} / \mathrm{kg}-\mathrm{cm}^{2} / \mathrm{MBq}-\mathrm{h}$ ) of the radionuclide $\left(\Gamma_{\mathrm{Br}}\right)$, Bremsstrahlung probability $\left[\left(P_{\mathrm{Br}}\right)_{\beta}\right]$ and the activities, $A_{\text {release, }}$ of current and potential therapeutic radionuclides below which patients can be released from medical confinement in bone cortical, bone compact, different regions of tooth enamel (enamel dentin junction (EDJ), enamel middle surface, enamel inner surface), different regions of dentin (outer surface, middle surface, enamel dentin junction (EDJ)), soft tissue, lungs and skeleton for different therapeutic beta-emitting radionuclides (Table 1) are calculated using equations (4)-(7) \& tabulated values of $Z_{\text {mod. }}$.

\section{Results and discussion}

The activities, $A_{\text {release, of current and potential therapeutic }}$ radionuclides below which patients can be released from medical confinement in Bone cortical, Bone compact, different regions of tooth enamel (enamel dentin junction (EDJ), enamel middle surface, enamel inner surface), different regions of dentin (outer surface, middle surface, enamel dentin junction (EDJ)), soft tissue, lungs and skeleton have been calculated for the $70 \mathrm{~kg}$ standard man and it is given in Tables 11 and 12. These values have been calculated assuming effective half-life of radionuclide, equals the physical half-life and an exposure factor of 0.25 at a distance from the patient of $1 \mathrm{~m}$. Calculated $A_{\text {release }}$ values are found to be large: on the order of thousands to millions of mega becquerels.

The evaluated values of $\Gamma_{\mathrm{Br}}$ in different regions of bone, different regions of tooth, soft tissue, lungs and skeleton are shown in Tables 7 and 8 respectively. The specific Bremsstrahlung constant is the exposure rate at a unit distance from a unit activity point source of bremsstrahlung in air emitting one $\beta$-ray of the specified maximum energy $\left(E_{\max }\right)_{\beta}$ per nuclear transformation and yielding bremsstrahlung of mean energy $\left(E_{\mathrm{Br}}\right)_{\beta}$. The calculated probability of a radiative energy loss (i.e., bremsstrahlung interaction) by each $\beta$-ray is given in Tables 9 and 10 .

The estimated values of specific Bremsstrahlung constant (in $\left.\mathrm{C} / \mathrm{kg}-\mathrm{cm}^{2} / \mathrm{MBq}-\mathrm{h}\right)$ of the radionuclide $\left(\Gamma_{\mathrm{Br}}\right)$, Bremsstrahlung probability $\left[\left(P_{\mathrm{Br}}\right)_{\beta}\right]$ and the activities, $A_{\text {release, of current and }}$ potential therapeutic radionuclides below which patients can be released from medical confinement for different regions of bone and tooth are greater than soft tissue. The proper localization is possible in bone and tooth, because production of Bremsstrahlung in different regions of teeth and bone are greater than the soft tissue due to presence of high $\mathrm{Z}$ elements (especially calcium) which leads to high modified atomic number $\left(Z_{\text {mod }}\right)$ which is the function of Bremsstrahlung yield (according to equation (1))

\section{Conclusion}

Proper localization and quantification of incorporated beta emitters in bone and tooth are possible, because Bremsstrahlung production is greater in bone and tooth than soft tissue due to their high modified atomic number $\left(Z_{\text {mod }}\right)$. For pure $\beta$-ray emitting therapeutic nuclides, the activities requiring medical confinement are large: on the order of hundreds of thousand to millions of mega Becquerels. But the patients receiving activities from radionuclides are only of the order hundred mega Becquerels because of probative radiation toxicity to the patient. Thus patients receiving $\beta$-ray therapy do not have to be hospitalized for radiation precautions.

\section{Acknowledgement}

The authors would like to thankfully acknowledge the support received from H.K.C. Shastry and Dr. N.C. Prasanna Kumar.

\section{References}

Christy, M., Eckerman, K.F., 1987. Specific Absorbed Fractions of Energy at Various Ages from Internal Photon Sources, vols. I-VII. Oak Ridge National laboratory, Oak Ridge. ORNL/TM8381.

Franssen, M.J.A.M., Barbooms, A.M.J., Karthous, R.P., et al., 1989. Treatment of pigmented villonodular synovitis of the knee with yatrium-90, silicate: prospective evaluation by arthroscopy, histology and technetium pertechnetate uptake measurements. Ann. Rheum. Dis. 40, 237-239.

Fritzberg, A.R., Wessels, B.W., 1995. Therapeutic radio nuclides. In: Wagner, H.N., Szabo, Z., Buchanan, J.W. (Eds.), Principles of Nuclear Medicine, second ed. WB Saunders, Philadelphia, P.A., pp. 229-235.

Hien Nguyen, Ghanem Ghanem, Renato Monandini, et al., 1997. Tumor type and vascularity important variables in infusional brachytherapy with colloidal 32-P. Int. J. Radiat. Oncol. Biol. Phys. 39, 481-487.

Johns, H.E., Cunningham, J.R., 1969. The Physics of Radiology, third ed. Charles C, Thomas, Springfield, IL. 164.

Lofquist, T., Peterson, C., Nilson, M., 1997. Radioactive synoviorthesis in patients with haemophilia factor inhibitor. Clin. Orthop. 343, 37-44.

Markowicz, A.A., VanGriken, R.E., 1984. Composition dependence of Bremsstrahlung background in electron-probe X-ray microanalysis. Anal. Chem. 56, 2049-2051.

Patrick, C., D'Haese, Van Landeghem, Glen F., Lamberts, Ludwig V., Bekaert, Vera A., Iris Schrooten, De Broe, Marc E., 1996. Measurement of strontium in serum, urine, bone, and soft tissues by Zeeman atomic absorption spectrometry. Clin. Chem. 43, 121-128.

Rodrigues-Merchan, E.C., Megalan, M., Golindo, E., 1997. Haemophilic synovitis of knee and the elbow. Clin. Orthop. 313, 47-53. 
Shivaramu, 1990. Modified Kramer's law for Bremsstrahlung produced by complete beta particle absorption in thick targets and compounds. J. Appl. Phys. 68 (1), $1225-1228$.

Stewart, J.S.W., Herd, V., Snook, et al., 1988. Introperitoneal iodine-131 and yttrium90 labelled monochlonal antibodies for ovarian cancer: pharmacokinetics and normal tissue dosimetry. Int. J. Cancer 371.

Uchiyama, Mayuki, Narita Hiroto, R.T., Makino, Motoji, Sekine, Hiroshi, Mori, Yataka, Fukumitsu, Nobuyoshi, Kawakami, Kenji, 1997. Strontium-89 therapy and imaging with bremsstrahlung in bone metastases. Clin. Nucl. Med. 22 (9), 605-609.
Vont Pad Bosch, P.J.L., Putte, L.B.A., Barbooms, A.M.J., et al., 1981. Radiosynoviorthesis in haemophillic joint diseases. J. Rheumatol. 40, 237-239.

Webber, D.A., Eckerman, K.F., Dillmaman, L.T., Ryman, J.C., 1989. MIRD; Radionuclide Data and Decay Schemes. Society of Nuclear Medicine, New York, NY.

Zanzonico, Pat B., Binkert, Barbara L., Goldsmith, Stanley J., 1999. Bremsstrahlung exposure from pure beta emitters. J. Nucl. Med. 40 (6), 1024.

Zanzonico, P.B., Brill, A.B., Becker, D.V., 1995. Radiation dosimetry. In: Wagner, H.N. Szaboz, Buchanan, J.W. (Eds.), Principle of Nuclear Medicine, second ed. WB Saunders, Philadelphia, P.A, pp. 106-134. 